\title{
Changes in the acoustic behavior of gray whales Eschrichtius robustus in response to noise
}

\author{
Marilyn Dahlheim ${ }^{1, *}$, Manuel Castellote ${ }^{2,3}$ \\ ${ }^{1}$ Alaska Fisheries Science Center, Marine Mammal Laboratory, 7600 Sand Point Way NE, Seattle, Washington 98115, USA \\ ${ }^{2}$ Joint Institute for the Study of the Atmosphere and Ocean (JISAO), University of Washington, \\ 3737 Brooklyn Avenue NE, Seattle, Washington 98105, USA \\ ${ }^{3}$ Alaska Fisheries Science Center, Marine Mammal Laboratory, 7600 Sand Point Way NE, Seattle, Washington 98115, USA
}

\begin{abstract}
Gray whales Eschrichtius robustus, while engaged in underwater signaling, circumvented noise in their environment by altering the structure and timing of their calls. Acoustic responses of whales to both naturally occurring and artificially increased levels of noise were documented during sound playback experimentation in San Ignacio Lagoon, Baja California Sur, Mexico. Nine acoustic parameters were examined and compared between experimental conditions: calling rates, call types, frequency range of calls $(\mathrm{Hz})$, call peak frequencies $(\mathrm{Hz})$, call received levels ( $\mathrm{dB}$ re $1 \mu \mathrm{Pa})$, call duration (s), percentage of calls showing frequency modulation, number of pulses per call, and call repetition rates (number of pulses $\mathrm{s}^{-1}$ ). Multiple acoustic strategies were employed by whales which enabled them to minimize the detrimental effect that noise had on their underwater signaling. When different sources of noise were added to their habitat, a corresponding increase was observed in calling rates, call received levels, frequency-modulated signals, number of pulses per call, and call repetition rates. Our results show that gray whales vary their calling behavior dependent upon the noise source, duration, and presentation. Acoustic responses to noise may also differ based on the behavioral activity of the whale (e.g. breeding, migrating, feeding) and on the habitat the whale is occupying (shallow lagoons, coastal or pelagic waters). Background noise (both natural and man-made) has a profound effect on the acoustic behavior of this coastal species and calling is modified to optimize signal transmission and reception. Whether these modifications ensure that effective communication takes place in higher noise situations, without causing detrimental effects to individuals in the long term, remains to be tested.
\end{abstract}

KEY WORDS: Gray whale $\cdot$ Acoustic behavior $\cdot$ Noise $\cdot$ Sound playback

\section{INTRODUCTION}

The dramatic increase in human-generated ocean noise over the last century has raised concerns about the potential negative impact that increased noise levels may have on marine mammals (Richardson et al. 1995, NRC 2003, 2005, Nowacek et al. 2007, Southall et al. 2007). Of particular concern is how these increased levels of noise could potentially impact the low-frequency specialists such as baleen whales (Clark et al. 2009). Ocean anthropogenic noise will most likely continue to increase, poten-

${ }^{*}$ Corresponding author: marilyn.dahlheim@noaa.gov tially to levels that could threaten marine mammals on a global scale.

Increased noise levels have the potential to interfere with or mask the acoustic signals of animals. Literature reviews on the effects of noise on animal communication report that many features of animal signals change under increased noise levels, thereby reducing the detrimental effect of noise on their communication signals (e.g. Brumm \& Slabbekoorn 2005, Barber et al. 2010, Bradbury \& Vehrencamp 2011, Shannon et al. 2016). Special attention has been paid to the impact of noise on the acoustic communi-

Outside the USA $\odot$ The USA Government 2016. Open Access under Creative Commons by Attribution Licence. Use, distribution and reproduction are unrestricted. Authors and original publication must be credited.

Publisher: Inter-Research · www.int-res.com 
cation of many species, including frogs (e.g. Tennessen et al. 2014), birds (e.g. Parris \& Schneider 2008), fish (Popper \& Hastings 2009), cetaceans (e.g. Richardson et al. 1995), and other mammals (Rabin et al. 2003). A collective review of these studies suggests that these various taxa minimize the effects of noise on their signaling by changes in either the relative timing of their signals or in the structure of their calls. These short-term behavioral responses improve signal detection and thus may contribute to maintaining successful communication in noisy habitats (Slabbekoorn 2013); however, the long-term sublethal effects of noise on reproduction and survival remain poorly understood (Kight \& Swaddle 2011). In addition to the impacts on acoustic behavior, elevated background noise can cause displacement from preferred or critical habitats (Bryant et al. 1984, Dahlheim 1987, Seip et al. 2007, Castellote et al. 2012). Adverse physical effects such as ear damage have also been demonstrated, as well as non-auditory physical effects such as physiological stress involving hormone responses leading to lowering of disease resistance, increased vulnerability to environmental stress, and hormone imbalances which may adversely affect reproduction (Creel et al. 2002, Rolland et al. 2012, Tennessen et al. 2014).

For marine mammals, especially cetaceans, hearing constitutes their most important sensory process. A reduction in signal transmission or reception can adversely affect the reproduction or even the survival of a given species that is dependent on such a sensory process. Thus, cetacean species, dependent on acoustic signaling for spacing, attracting, effective foraging, or alerting functions must overcome or be able to circumvent noise.

Several studies have shown high sensitivity to anthropogenic noise by mysticetes. The Lombard effect, where signalers modify vocal characteristics such as level, pitch, and/or rate of signal production in a noisy environment to improve signal detection (Lombard 1911), has been described for North Atlantic right whales Eubalaena glacialis (Parks et al. 2011), and humpback whale Megaptera novaeangliae (Dunlop et al. 2014). Parks et al. (2007) examined both short-term and long-term behavioral responses in calls produced by North Atlantic right whales and South Atlantic right whales E. australis in the presence of low-frequency noise. In high noise situations, right whales were documented to shift to a higher average fundamental frequency and call at a lower rate. The study indicated that right whales may shift call frequency to compensate for increased band-limited background noise. McDonald et al.
(2009) suggested shipping noise as one of many explanations for a long-term decrease in the fundamental frequency of eastern North Pacific blue whale Balaenoptera musculus song. Blue whales were found to call more consistently in the presence of seismic exploration noise, suggesting that this response may represent a compensatory behavior on the part of the whales to the elevated ambient noise (Di Iorio \& Clark 2010). Fin whale B. physalus acoustic communication was modified to compensate for increased background noise by both chronic shipping noise and acute seismic survey noise. Blackwell et al. (2015) documented changes in bowhead whale Balaena mysticetus calling rates during the gradual increase of seismic airgun activity in the Beaufort Sea. The whales increased their calling rate until a plateau was reached, followed by a decrease until calling ceased while noise levels continued to increase. Noise has also been shown to impact whales by causing them to move out of the area. Castellote et al. (2012) documented a major displacement of Mediterranean fin whales by seismic survey noise that persisted for a time period well beyond the duration of the disturbance. For gray whales Eschrichtius robustus, surface behavioral reactions to underwater noise have been directly observed for multiple activities such as oil and gas exploration and production, aircraft overflights, and a variety of vessel activities including whale watching and dredging (Bryant et al. 1984, Malme et al. 1989, Moore \& Clark 2002). Dahlheim (1987) documented a significant decline in the number of gray whales occupying Laguna San Ignacio during noise playback experimentation.

The gray whale, due to its preferred coastal habitat, is exposed to a dynamic acoustic environment. As this species undergoes its annual migration from Alaska waters to the lagoons of Mexico it encounters a wide spectrum of both naturally occurring and man-made sounds. Gray whale calls have been described from both the southern and northern regions of its habitat (Dahlheim et al. 1984, Moore \& Ljungblad 1984), with most vocal activity occurring on the southern breeding and calving grounds. Within the shallow waters of Laguna San Ignacio, calls of gray whales most likely are heard and used by conspecifics within a $5-6$ mile $(8-9.7 \mathrm{~km})$ distance. The distance over which different calls are produced and heard most likely varies in different coastal habitats. Throughout the species' range, the function of their calls is unknown. Given grey whales' limited call repertoire (i.e. 6 call types) and frequency range of the calls $(40 \mathrm{~Hz}$ to $4 \mathrm{kHz}$ ) (Dahlheim et al. 1984, Moore \& Ljungblad 1984), what, if any, strategies 
could be employed by this species to successfully circumvent noise in its environment so that signal transmission and reception would remain effective?

Following a 2-yr study conducted in 1981 and 1982 in Laguna San Ignacio, Baja, California Sur, Mexico, which documented both the gray whales' acoustic repertoire and the ambient noise conditions in the lagoon (Dahlheim et al. 1984, Dahlheim 1987), acoustic responses of gray whales to both naturally occurring and artificially increased levels of noise were investigated. Different noise sources were introduced into the lagoon through a series of experimental playback sessions. Gray whale acoustic responses to both shortterm playbacks and long-term playbacks were quantified and compared among experimental periods. Comparisons were made between simulated skiff noise (playback experiments) and real sound sources (larger vessels and skiffs present in the study area) to determine the feasibility of using playback techniques to assess the effect of noise on the acoustic capabilities of marine mammals. The hypothesis during this study was that the gray whale, while engaged in underwater calling, circumvented noise by altering the structure and timing of its calls.

\section{MATERIALS AND METHODS}

\section{Study area}

Laguna San Ignacio, Baja California Sur, Mexico, located along the Pacific coast of Baja California approximately $680 \mathrm{~km}$ south of San Diego, California, is one of the major breeding and calving areas for gray whales (Jones \& Swartz 1984) (Fig. 1). A detailed description of the lagoon is provided in Jones \& Swartz (1984) and is briefly summarized here. Laguna San Ignacio is a system of narrow, relatively deep channels surrounded by large intertidal flats. The lagoon lies on a north-south axis and extends inland approximately $32 \mathrm{~km}$ and ranges in width from 1.8 to $6.5 \mathrm{~km}$. The bathymetry and sedimentology is divided into 5 areas: the inlet, east channel, and the lower, middle, and upper lagoon (Figs. 1 \& 2). Our shore-based station at Rocky Point (Punta Piedra) lies between the lower and middle lagoon. The lagoon narrows at this point to a constricted width of only $1.8 \mathrm{~km}$. In the lower lagoon and areas just west of Rocky Point the bottom is composed of poorly sorted coarse and medium grained sand with crushed shells. Just west of Rocky Point, medium-grained sand ridges are interspersed with occasional rock outcroppings. The study area was an

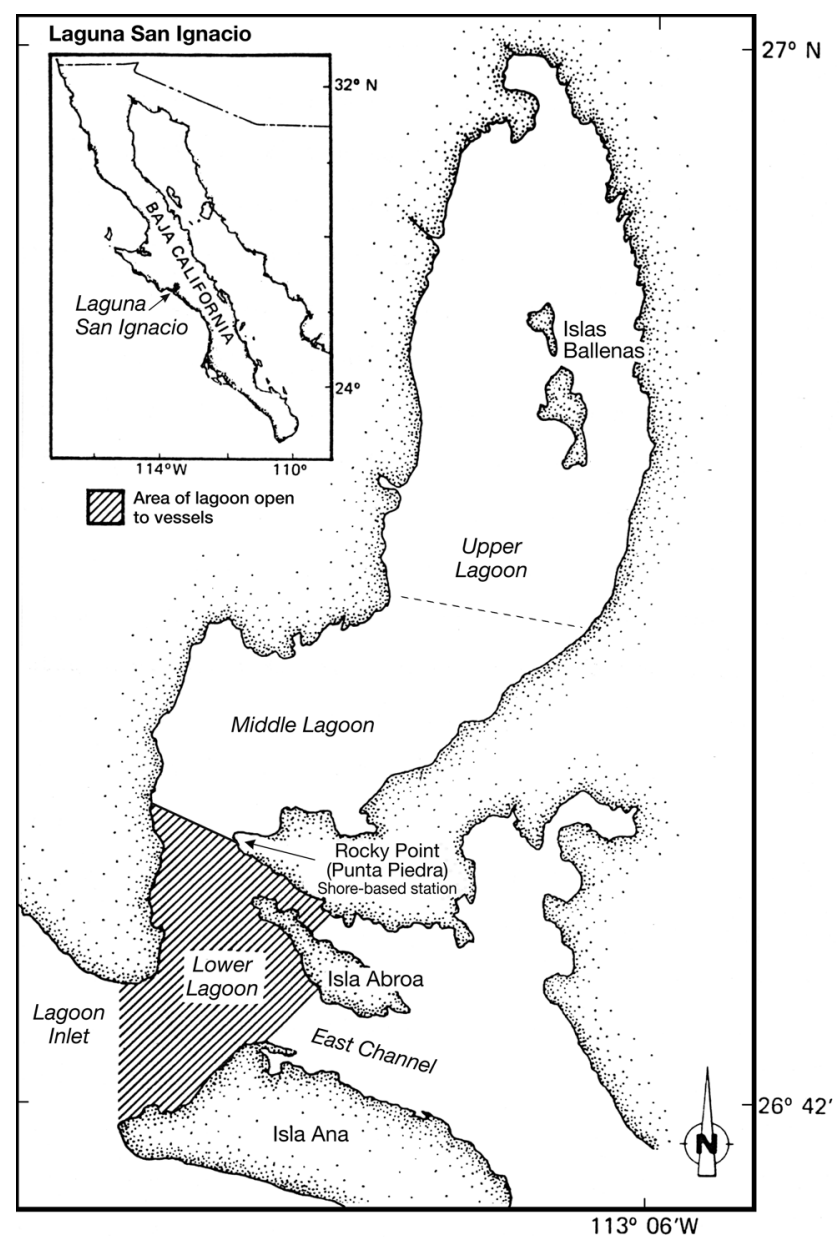

Fig. 1. Site for study of the acoustic behavior of gray whales Eschrichtius robustus in response to noise in Laguna San Ignacio, Baja California Sur, Mexico

ideal location for the proposed research. This area is visited approximately by 200 to 400 whales each year and is a focal point of tourism, which allowed for monitoring of gray whale calls and ambient noise on days with and without vessel activity (i.e. when vessels were confined to the lower lagoon).

\section{Acoustic equipment}

A Nagra IV-SJS, reel-to-reel analog tape recorder, coupled with a KSP hydrophone (Model HS-107/222 with a flat frequency response from $40 \mathrm{~Hz}$ to $19 \mathrm{kHz}$ $\pm 3 \mathrm{~dB}$ and a sensitivity of $-194 \mathrm{~dB}$ re $1 \mu \mathrm{Pa} \mathrm{V}^{-1}$ ) and attenuator, were used to collect the underwater sounds prevalent in the lagoon environment. Ampex 456 audio tape was selected. The hydrophone was bottom mounted at a depth of $8 \mathrm{~m}$ and suspended up from the bottom by a float set at $3 \mathrm{~m}$ located near an 


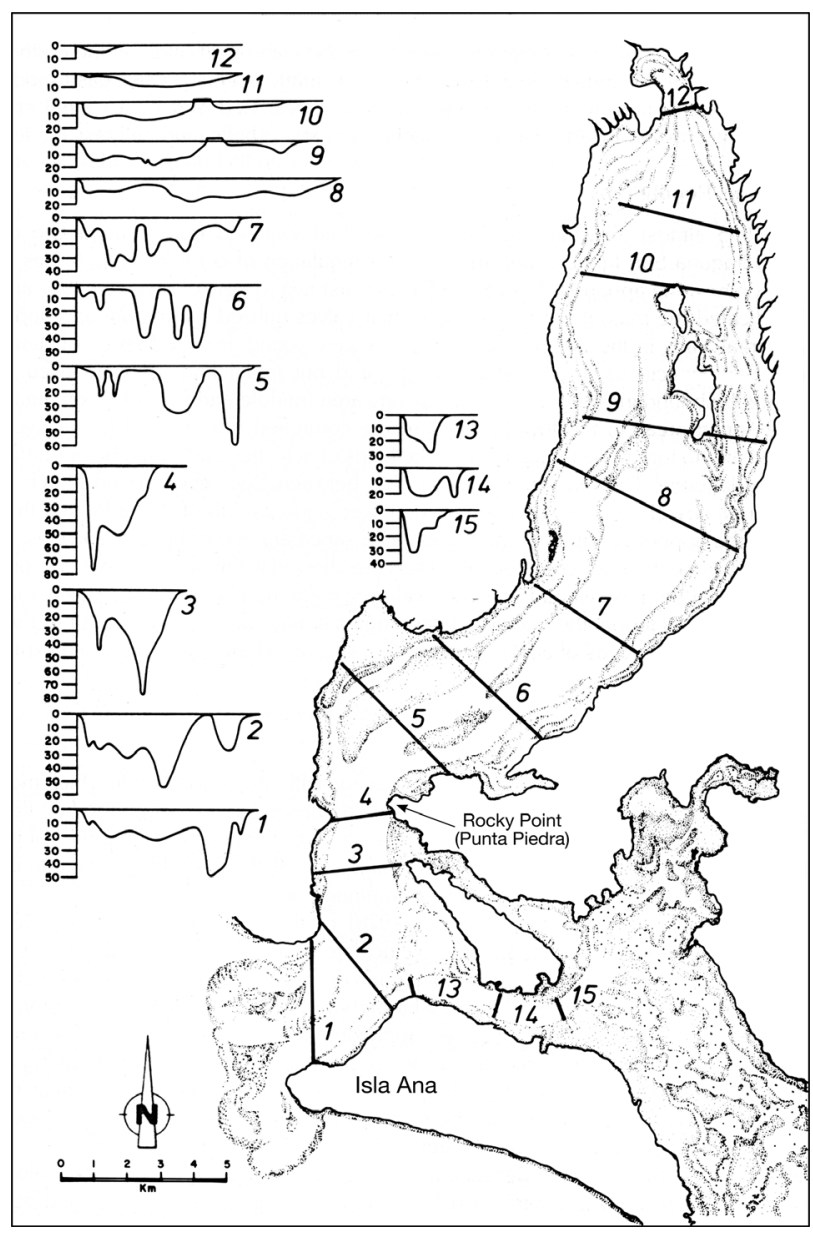

Fig. 2. Depth profiles (feet; 1 foot $\approx 0.3 \mathrm{~m}$ ) of Laguna San Ignacio based on echograms. The horizontal scale is approximate (Source: Jones \& Swartz 1984). The division into 15 areas depicts variation in bottom contours at systematic intervals along the length of the lagoon

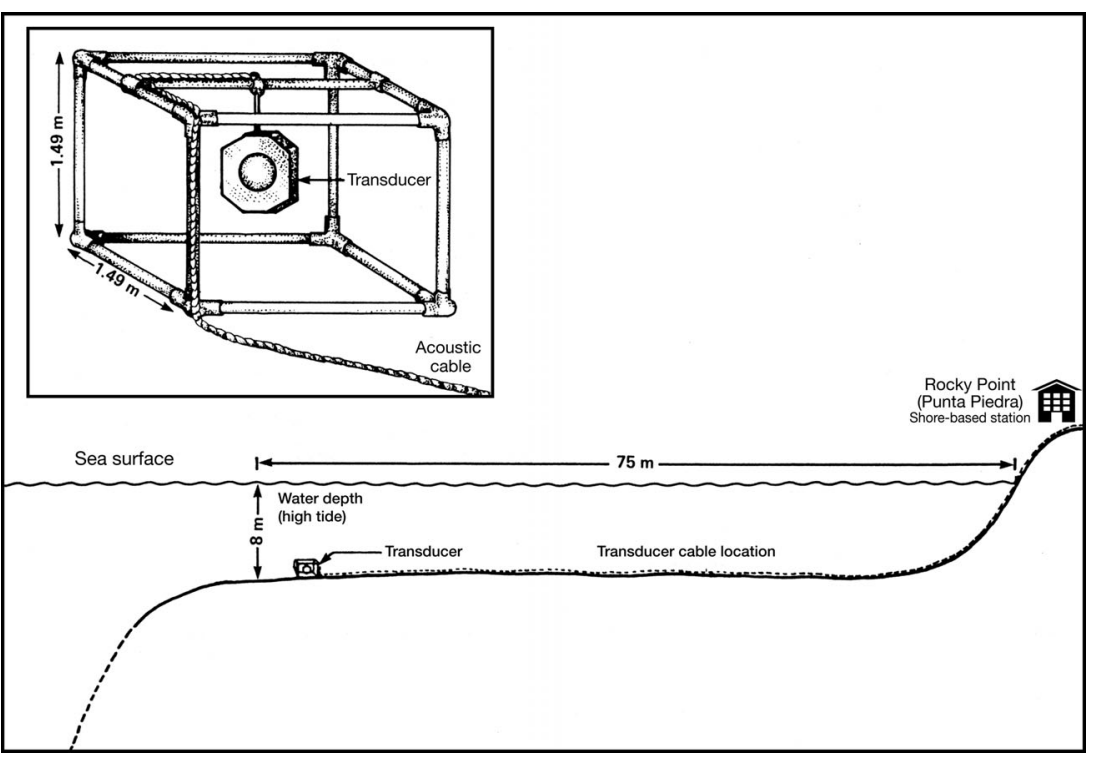

acoustic transducer (Lubell, Model 98) used for playback investigations (Fig. 3). The associated cable was weighted down and extended $25 \mathrm{~m}$ following the bottom contour of the lagoon and terminating at the shore-based station. This bottom-mounted hydrophone design provided (1) a reduction in system noise (i.e. lessening the effect of hydrophone acceleration), (2) less likelihood, compared with a floating platform, of interfering with the whales' normal behavior, and (3) a 24-h recording and monitoring system. The underwater cable terminated at Rocky Point, an elevated shore-based station where our acoustic instrumentation was placed. Simultaneous narratives accompanied each recording. This calibrated receiving system provided an effective response of $25 \mathrm{~Hz}$ to $10 \mathrm{kHz} \pm 2 \mathrm{~dB}$ at $9.5 \mathrm{~cm} \mathrm{~s}^{-1}$ tape speed and $25 \mathrm{~Hz}$ to $20 \mathrm{kHz} \pm 2 \mathrm{~dB}$ at $19 \mathrm{~cm} \mathrm{~s}^{-1}$.

During playback investigations, the underwater acoustic transducer was bottom-mounted at a distance of $75 \mathrm{~m}$ off the farthest promontory available near the Rocky Point shore-based station (Fig. 3). To ensure proper depth, bottom placement and equipment safety, the transducer was affixed to a $1.5 \times$ $1.5 \mathrm{~m}$ square of PVC pipe. Several holes were drilled into this pipe, allowing water to enter into this structure as it was being submerged. A diver was used to guide the transducer cage (in an upright position) to the lagoon bottom. Once the structure was in contact with the bottom, the diver placed 4 sand-filled burlap sacks over each lower leg of the cage to secure its location. This anchorage system ensured that no movement of the equipment took place in the strong tidal currents. The measured depth at high tide of this transducer was $8 \mathrm{~m}$, within the depth range specifications required by the manufacturer of this transducer. An average tidal range of $3 \mathrm{~m}$ was documented in the lagoon. The transducer cable was weighted down at 5 to $6 \mathrm{~m}$ intervals running from the cage along the lagoon bottom to the shore-based station at Rocky Point. The design of the cage and cable anchorage system ensured that a whale could not become entangled in the acoustic equipment.

Fig. 3. Bottom-mounted transducer in Laguna San Ignacio, Baja California Sur, Mexico, used for playback of recorded sounds to study the response of gray whales Eschrichtius robustus to noise 
The shore-based playback equipment consisted of a transmitter (Acoustic Systems, Model TS107), driven by a $12 \mathrm{~V}$ deep-cycle marine battery. Three fully charged batteries were rotated throughout the day to ensure full power to the system. Recharging of all batteries occurred daily using a Briggs and Stratton $(40 \mathrm{~W})$ generator built for recharging purposes. The level of the projected sounds could be adjusted by the use of the gain on the transmitter, spanning the range of 40 to $150 \mathrm{~dB}$ re $1 \mu \mathrm{Pa}$, with levels varying with frequency. The transmitter was also equipped with a built-in calibration or test tone. The test tone was composed of a $1 \mathrm{~s}$ upsweep followed by a $31 \mathrm{~s}$ downsweep. The signal was composed of a fundamental component and multiple harmonics (Fig. 4B). The fundamental component started at $1000 \mathrm{~Hz}$, peaked at $1160 \mathrm{~Hz}$ and ended at $562 \mathrm{~Hz}$. The 8th harmonic was the highest band visible in the spectrogram. It started at $9351 \mathrm{~Hz}$, peaked at $10 \mathrm{kHz}$ and ended at $1476 \mathrm{~Hz}$. The input terminals of the transmitter were connected to a Nakamichi 550 cassette recorder. The frequency response of the cassette recorded was $40 \mathrm{~Hz}$ to $19 \mathrm{kHz} \pm 2 \mathrm{~dB}$. The frequency response of the acoustic transducer was $200 \mathrm{~Hz}$ to $5 \mathrm{kHz} \pm 3 \mathrm{~dB}$ and maximum source level of $180 \mathrm{~dB}$ re $1 \mu \mathrm{Pa} \mathrm{m}-1$.

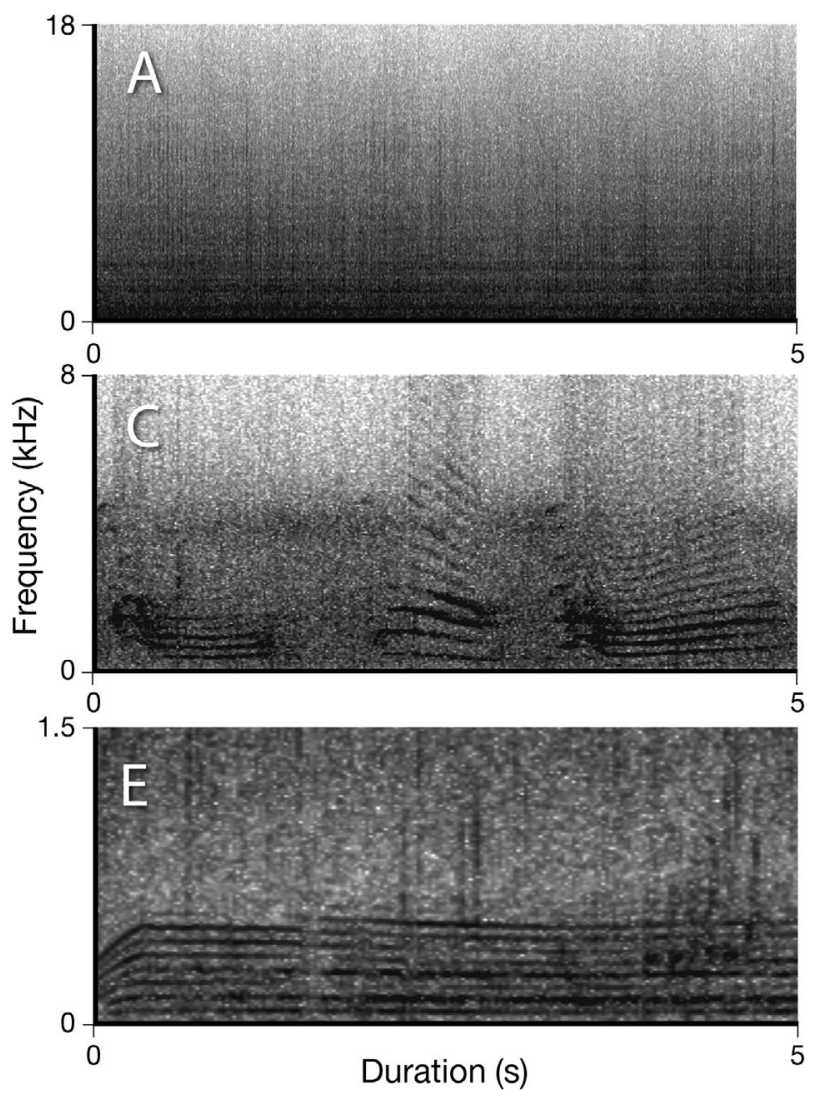

\section{Short-term experimental design}

In 1983, during the months of January and February, the effect of short-term noise stimuli on the acoustic behavior of gray whales was investigated. During playback sessions that spanned different times of the day and tide cycles, the experimental design employed a pre-trial, trial, and post-trial period, each with a duration of $15 \mathrm{~min}$. Sounds were projected back only during trial periods, the onset of which was rapid and of short duration. The playback experiments included the projection of biological and non-biological sound sources. During biological sound playback periods, gray whale calls (previously collected in Laguna San Ignacio) were projected back. The biological playback schedule during this trial period consisted of $1 \mathrm{~min}$ of playback followed by 1 min of silence, to prevent confusion during analysis. Thus for a $15 \mathrm{~min}$ interval, sounds were projected for a total of $8 \mathrm{~min}$. Non-biological sound sources included outboard engine noise (collected in Laguna San Ignacio), projected for $15 \mathrm{~min}$, and test tones (calibration tone on the acoustic amplifier, 1 tone produced every minute). Example spectrograms for each sound source are shown in Fig. 4. Recordings of these playback tapes
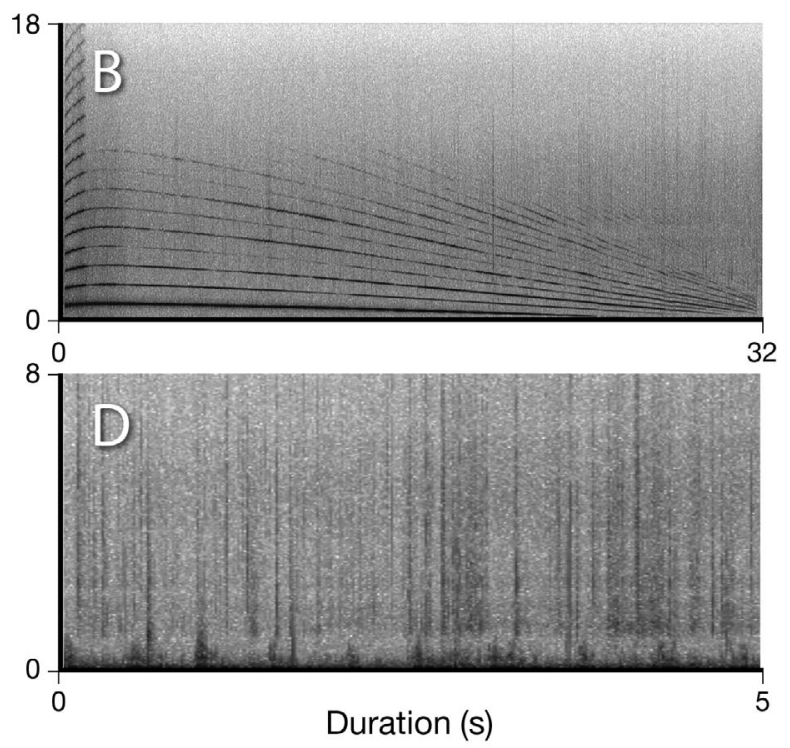

Fig. 4. Example spectrograms of (A) real sources, (B) test tones, (C) transient killer whales, (D) oil-drilling sounds, and (E) outboard engine noise. Spectrogram characteristics: Hanning window, 512 fast Fourier transform (FFT) data points for $\mathrm{A}$ and $\mathrm{B}, 256 \mathrm{FFT}$ for $\mathrm{C}$ and $\mathrm{D}$, and $128 \mathrm{FFT}$ for $\mathrm{E}$. Note frequency axis varies among panels 
were made through the bottom-mounted hydrophone system previously described. All sound stimuli were projected at maximum levels which ensured that the whales within the immediate area (within $1 / 2$ mile, $0.8 \mathrm{~km}$, radius) were exposed to a minimum sound level of at least $130 \mathrm{~dB}$ re $1 \mu \mathrm{Pa}$. Expected received levels, based on actual measurements, were determined through a series of propagation experiments described by Dahlheim (1987). Playback experiments were terminated when: (1) Beaufort conditions created noise interference, and (2) noise from unplanned vessel and skiff traffic interfered with the experiments.

In addition to playback experiments, gray whale recordings were also collected in the presence and absence of real man-made noise sources in the lagoon (e.g. 25-30 m tourist vessels and tourist and fishing skiff noise; Fig. 4A,E). The collection of gray whale calls during the absence of vessel noise served as an additional control. Intra- and inter-experimental controls (e.g. both pre-trials and absence of extraneous vessel sources) were compared to experimental conditions (playback trials and presence of vessels). Comparisons were also made between simulated outboard engine noise and real outboard engine noise to determine if the simulated noise source elicited the same responses by whales. When the calling behavior changed during trial periods, post-trial periods were also compared between and among various experiments to determine when calling behavior returned to pre-trial levels.

\section{Analysis of acoustic responses to short-term noise exposure}

All recordings were edited and information transferred to a written log. These logs recorded tape identification number, date and time, types of sound produced and a written narrative of all pertinent comments (e.g. sea state, tidal conditions, and presence of vessels in the area). Once completed, these edit logs were grouped by experiment. Five experimental groupings were defined: (1) Control or pretrial periods: no intervention of man-made noise into the environment. Pre-trials were completed for all sound stimuli except for Expt A when control periods were compared to both trials and post-trials; (2) Expt A: real man-made sound sources, including larger vessel noise (25-30 m tourist vessels) and skiff noise; (3) Expt B: projection of outboard engine noise; (4) Expt C: projection of gray whale sounds; (5) Expt D: projection of test tone
This pre-trial (or control period as described above), trial, and post-trial experimental approach allowed acoustic comparisons to be made between and within each experiment. Within each experiment, data were further grouped for each test period. For Expt A, modifications in this approach were needed given that trial periods for real sources only took place when tour vessels were within 1-2 miles $(1.6-3.2 \mathrm{~km})$ of our shore-based station. For pre-trial values we used data collected during control periods. Post-trials occurred when vessels were still present but outside the 1 mile radius. For each experimental grouping, the following measurements were made on gray whale calls: (1) total number of calls produced (i.e. calling rate), (2) type of call produced, and (3) structural changes within calls. Variables approximated a normal distribution (KolmogorovSmirnov [K-S] test, $\mathrm{p}>0.05$ ), thus allowing statistical comparisons using parametric tests following Sokal \& Rohlf (1969) and Zar (1974). Statistical tests were conducted with the use of an IBM/XT computer using the Number Cruncher Statistical System Software (NCSS, Version 4.2).

During the projection of various sound stimuli, the zone of influence of potential acoustic interference exceeded the visual capabilities of the observers. Thus, no estimate could be made regarding the number of the animals potentially impacted by increased noise levels. A dense concentration of animals, ranging from 200 to 400 whales, occurs in a relatively small area (approximately $56 \mathrm{~km}$ in length by $10 \mathrm{~km}$ in width). We, of course, could not control or estimate the total number of whales present during experimentation periods. An assumption was made that the number of whales (to include calves) remained constant over the course of the study.

\section{Calling rates}

The total number of whale calls per experiment and per test period (pre-trial, trial and post-trial) was calculated by hand-scoring each call produced. Forty-two calls from each of the 3 test periods were selected from various times and days throughout the study period. The average number of calls produced per 15 min interval was then calculated. The resultant averages were compared (Student's $t$-test and 1-way ANOVA) for each test period and among experiments to determine if statistically significant differences occurred in the calling behavior of gray whales when exposed to different sound stimuli. 


\section{Call type}

Six call types have been shown to be produced by gray whales on their breeding grounds (Dahlheim et al. 1984). To determine if gray whales switched call types in the presence of noise, data on the type of call produced were summarized from each log sheet for each experimental condition described above. The percentage of a specific call type produced was then calculated, thereby illustrating the overall use of a specific call type for each event. These percentages were compared within and among experiments.

\section{Call structure}

To determine if gray whales modified their calling structure, the following 7 acoustic parameters were investigated: overall frequency range of signal $(\mathrm{Hz})$, peak frequency range $(\mathrm{Hz})$, received levels $(\mathrm{dB}$ re $1 \mu \mathrm{Pa})$, number/percentage of calls showing frequency modulation, call duration (s), number of pulses per call, and call repetition rates (number of pulses produced per second). Overall frequency ranges, peak frequencies, call duration, and number of pulses per call were calculated directly off sonograms using a Sona-Graph (Kay Elemetrics, Model 7029A) (Fig. 5). Repetition rates were derived from the average call duration and the average number of pulses produced per call. For frequency modulation, the presence or absence of frequency modulation within the call was noted. A percentage was then calculated for the number of calls exhibiting frequency modulation within each experiment. To determine received levels of calls, average sound pressure level was computed using a fast Fourier transform (FFT) spectrum analyzer (Nicolet Scientific Corporation, Model 446). Displays of calculated spectra were made on an $x / y$ plotter and an average received level was calculated over the upper and lower frequency boundaries of each gray whale call (which in general ranged between 100 and $2000 \mathrm{~Hz}_{\text {; }}$ see Table 2) for all experiments.

A matrix was established listing the average values calculated for each of the 7 acoustic variables. Statistical comparisons (Student's $t$-test and chi square) were made to determine if significant changes occurred in the call structure of gray whale signals among experimental conditions (pre-trial, trial and post-trial playback periods). The same statistical comparisons were also made to determine if significant changes occurred in the call structure of gray whale signals among the different sound sources.

\section{Long-term experimental design}

In January and February 1984, we investigated gray whale acoustic responses to long-term noise stimuli which represented more of a gradual onset of noise. This approach allowed us to determine if gray whales employed different acoustic strategies when noise exposure time was increased or presented in another way. Sounds were projected back using the same acoustic equipment as that described for shortterm playback research.

The experimental design employed control periods 6 to $8 \mathrm{~h}$ in duration with playbacks occurring at different times of the day and tide cycles. Control periods spanned different times of the day to ensure that results were not affected by diel trends in gray whale sound production. Control periods were defined as times without any intervention of man-made noise (either real sources or projected sounds). Playback experiments included the projection of biological as

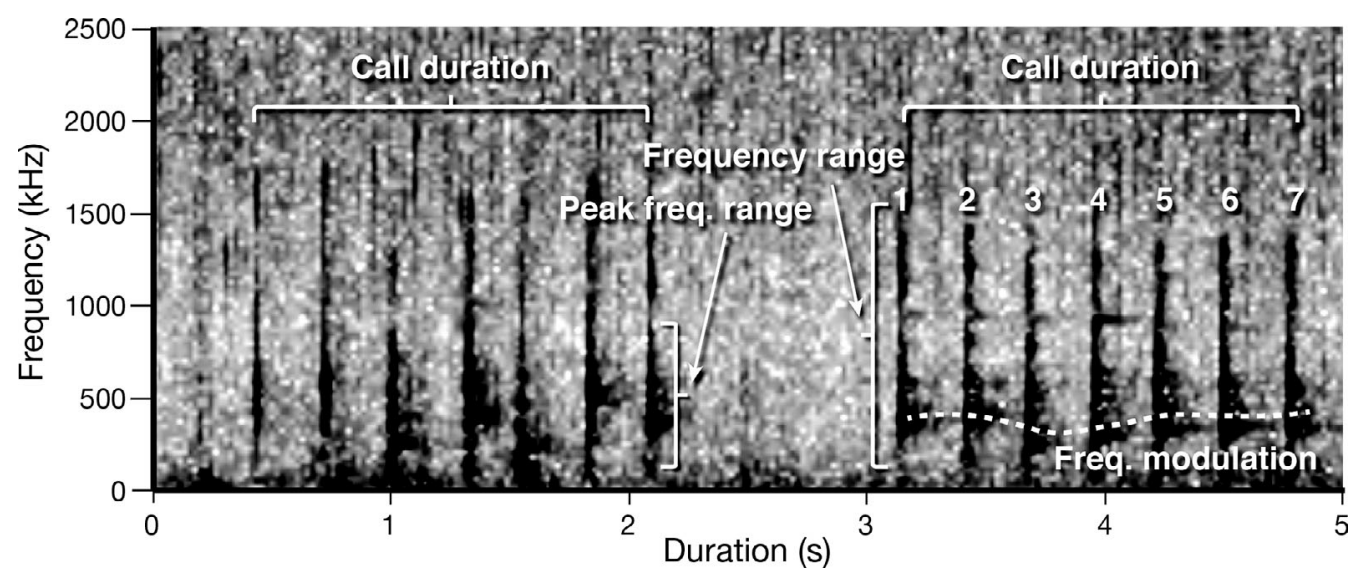

Fig. 5. Gray whale S1 call spectrogram depicting call measurements made during experimental test periods. Spectrogram characteristics: Hanning window, 256 FFT 
well as non-biological sound sources. During biological playback, transient killer whale Orcinus orca sounds recorded in Washington State were projected back to gray whales (Fig. 4C). Transient killer whales are known predators of gray whales (Jefferson et al. 1991) and it was assumed that this particular playback would result in a negative reaction by gray whales which, in turn, could provide an important interpretive element to the study. Anecdotal accounts have documented the occurrence of transient killer whales within the breeding lagoons, and killer whales are typically found in the coastal waters off Mexico.

Two types of man-made noise sources were projected. These included outboard engine noise (same tape as that used in the short-term study; Fig. 4E) and oil-drilling sounds (collected in the Beaufort Sea; Fig. 4D). These 2 man-made sources dominated frequencies less than $2 \mathrm{kHz}$ and thus potentially competed in the same frequency bands as signals produced by gray whales. To verify that gray whales were not responding to the power generated by the transducer during playback experiments (i.e. electromagnetic field or hum noise), the transducer was turned on for periods of up to $8 \mathrm{~h}$ but no sounds were projected.

Recordings were also made in the presence of the larger tourist vessels and skiffs (real sources) that occurred in the study area (Fig. 4A). These sources were compared between control periods and experimental conditions. Experimental testing was terminated under the same conditions as those listed for short-term studies.

\section{Analysis of acoustic responses to long-term noise exposure}

Analysis of long-term noise experiments followed the same methods as those described for short-term noise studies. Six experimental groupings were defined during long-term noise exposure with groupings: (1) Control: no intervention of real man-made noise into the environment; (2) Expt A: real man-made sound sources to include larger vessel noise (25$30 \mathrm{~m}$ tourist vessels) and tour or fishing skiff noise; (3) Expt B: projection of outboard engine noise; (4) Expt C: projection of oil-drilling sounds; (5) Expt D: projection of killer whale sounds; (6) Expt E: equipment on, no sounds projected

The long-term exposure design did not employ a post-trial period, thus statistical comparisons were only made between control and trial periods (Student's $t$-test and chi square). For each long-term ex- periment, 80 calls were selected from different times and days during the study period. The following sound parameters were inspected: calling rates, call type, and the same call structure parameters as those described for the short-term experiment. Analysis also included comparisons between the gray whales' acoustic responses to both short and long-term noise sources.

\section{RESULTS}

\section{Short-term noise exposure}

$$
\text { Calling rates and call type }
$$

The total duration of the short-term noise investigations was $52.5 \mathrm{~h}$. Each pre-trial, trial, and post-trial period represented $3.5 \mathrm{~h}$. This value was divided by 15 min intervals to represent an individual experiment; thus 14 experiments were accomplished for each experimental period. The $\mathrm{S} 1$ call dominated the whales' repertoire under all conditions (85 to $90 \%$ ), thus this phonation was the only one examined when investigating calling rates.

When pre-trial and trial periods were compared, calling rates were shown to significantly increase in the presence of large vessels and skiffs (i.e. real sources), and during the projection of both outboard engine noise and playbacks of gray whale sounds. During the projection of the test tones, all calling ceased. By the end of the post-trial period, call rates gradually returned to pre-trial values for both real sources and outboard engine playback; however, call rates were still significantly higher than in pre-trial periods. Post-trial call rates documented during gray whale playbacks did not differ from pre-trial values. During post-trials for test tone experiments, gray whales remained silent for at least $10 \mathrm{~min}$. Calling increased during the last $5 \mathrm{~min}$ of the post-trial period with significantly lower rates than those observed during pre-trial periods. Statistical values are shown in Table S1 in the Supplement at www.int-res.com/ articles/suppl/n031p227_supp.pdf.

When comparing calling rates for trial periods among the various experiments the highest rate of calling occurred during the projection of outboard engine noise. Calling rates were not significantly different when real sources and outboard engine playbacks were compared; however, both of these rates were significantly higher than the rates reported during the projection of gray whale calls. During posttrial periods, calling rates in the presence of real 
sources were significantly higher than the rates documented during the playbacks of outboard engine noise, gray whales sounds, and test tones. Table 1 summarizes calling rate differences within and among experiments. Statistical values can be found in Table S2.

\section{Call structure}

When pre-trial and trial periods were compared, several structural modifications were made in the calls produced by gray whales, with the type of change dependent upon the noise source. In the presence of real sound sources, significant changes were found in received levels, in the number of frequency-modulated calls, and in the number of pulses produced per call. The increase of call received levels was interpreted as an increase of the source level by whales exposed to noise, rather than whales approaching the hydrophone area. Repetition rates also increased as a result of the increasing number of pulses per call, given that no change was noted in call duration. During the projection of outboard engine noise, significant changes were once again found in call received levels and the number of pulses per call; however, the number of calls exhibiting frequency modulation did not differ. Again, the increase documented in the number of pulses per call resulted in a higher repetition rate, given that no change occurred in call duration. Significant structural changes also occurred during the projection of gray whale calls, with an increase documented in received levels, the number of frequency-modulated calls, and the number of pulses per call. No obvious differences could be found for call duration and repetition rates. Given that all calling ceased during the projection of the test tones, structural comparisons could not be made in this case.

Structural changes in gray whale calls were also examined between pre-trial and post-trial periods. After exposure to real sources, significant changes were still occurring in received levels and the number of pulses produced per call. Following outboard engine playbacks, a significant change was only found in the number of pulses produced per call. When comparing pre- and post-trials after the projection of gray whale sounds, no significant differences were found. After exposure to test tones, gray whales started to call again (approximately $10 \mathrm{~min}$ after the termination of the trial period) with the structure of the S1 call similar to that reported for pre-trial periods.

When comparing structural call changes made among the 4 different sound sources during trial periods, received levels were significantly higher in the presence of outboard engine playbacks than those levels documented for real sources. Received levels, however, were significantly higher for real sources than those obtained during the projection of gray whale sounds. The number or percentage of frequency-modulated calls was similar between real and outboard engine playbacks, with significantly higher numbers noted during the projection of gray whale calls. The number of pulses per call was not significantly different between real sources and outboard engine playbacks but was shown to be significantly higher during gray whale sound playbacks.

A comparison of structural changes observed during post-trials among the 4 sound sources yielded the

Table 1. Average call rates produced by gray whales Eschrichtius robustus in response to different types of noise in Laguna San Ignacio, Baja California Sur, Mexico. Data is based on type S1 calls (see Fig. 5) which accounted for more than $85 \%$ of all calls produced by gray whales over the course of the experiments. Standard deviations are shown in parenthesis. Short-term call rates are multiplied by 4 to obtain calls per hour when comparing short-term to long-term experiments. Significant differences $\left({ }^{*} \mathrm{p}<0.05\right)$ across experimental conditions (pre-trial-post) for short-term experiment, control-trial for long-term experiment and short-long term

\begin{tabular}{|c|c|c|c|c|c|c|c|}
\hline \multirow[t]{2}{*}{ Experiment } & \multicolumn{3}{|c|}{ Short-term (calls per15 min) } & \multicolumn{2}{|c|}{ Long-term (calls $\mathrm{h}^{-1}$ ) } & \multicolumn{2}{|c|}{$\begin{array}{c}\text { Short vs. long-term } \\
\text { trial comparisons }\end{array}$} \\
\hline & Pre-trial & Trial & Post-trial & Control & Trial & Short-term & Long-term \\
\hline Control & $18.8(5.5)$ & $18.6(4.9)$ & $18.0(5.2)$ & & & $73.6(19.2)$ & $81.4(16.6)$ \\
\hline Real sources & $17.3(5.2)$ & $41.9(10.9)^{*}$ & $29.6(3.8)^{*}$ & $81.4(16.6)$ & $159.6(35.5)^{*}$ & $167.6(43.6)$ & $159.6(35.5)$ \\
\hline Outboard & $19.7(3.4)$ & $45.5(11.3)^{*}$ & $24.9(4.3)^{*}$ & $81.4(16.6)$ & $137.9(24.7)^{*}$ & $182.0(45.2)^{*}$ & $137.9(24.7)^{*}$ \\
\hline Gray whales & $17.6(4.4)$ & $23.9(5.9)^{*}$ & $19.8(3.1)$ & & & $95.6(23.6)$ & \\
\hline Test tone & $18.7(4.7)$ & Ceased calling & $15.2(3.7)^{*}$ & & & & \\
\hline Oil drilling & & & & $81.4(16.6)$ & $14.9(7.4)^{*}$ & & $14.9(7.4)$ \\
\hline Killer whale & & & & $81.4(16.6)$ & Ceased calling & & \\
\hline Equipment on & & & & $81.4(16.6)$ & $78.5(17.0)$ & & \\
\hline
\end{tabular}


following. Received levels and the number of pulses per call for real sources were found to be significantly higher than those obtained for all other experiments. Significant differences were not found when comparisons were made among all experiments for either the number of frequency modulated calls or for duration. When outboard engine playbacks were compared to playbacks of gray whales sounds no differences were found in received levels, the number of frequencymodulated signals, or duration. However, the number of pulses per call was significantly higher in the presence of outboard noise. When outboard engine playbacks were compared to the playback of test tones, received levels and number of pulses per call were shown to be significantly higher in the presence of outboard engine sounds. Significant differences were not found between outboard engine and test tone playbacks for either the number of frequency-modulated signals or duration. When gray whales' sounds were compared against test tones, a significantly higher received level was found during gray whale playback periods. No differences were found between gray whales and test tones for percent frequency-modulated signals, duration, and number of pulses per call. A review of these combined values suggests that gray whales return to pre-trial values faster in the presence of their own sounds versus man-made sound stimuli. Table 2 summarizes call structural differences within and among experiments and between short and long-term experiments. Resultant statistical values are shown in Tables S3 \& S4.

\section{Long-term noise exposure}

\section{Calling rates and call type}

To assess the impact of long-term noise on the calls produced by gray whales $40 \mathrm{~h}$ were spent collecting data from each experimental period. For each experiment, $80 \mathrm{~S} 1$ calls were selected from different times and days to minimize the likelihood that they were produced by 1 or 2 whales. Similar to the previous season, the $\mathrm{S} 1$ call dominated the call repertoire of the gray whale ( $85 \%$ of all calls produced).

When compared to pre-trial periods, calling rates were shown to significantly increase both in the presence of real sources and during the projection of outboard engine noise. During the projection of oil-drilling sounds, a significant decrease in calling occurred. The projection of killer whale sounds resulted in an even greater effect on the acoustic behavior of gray whales; all calling ceased. Significant differences were not detected between control and trial periods for Expt E (equipment on with no projection of sounds).

\section{Calling rate comparisons between short- and long-term noise exposure}

Calling rates produced between short-term and long-term experiments were also compared. Significant differences could not be found when comparing call rates for real sources between short and longterm experimentation. However, call rates during short-term exposure to outboard engine noise were significantly higher than those documented during long-term experiments. Table 1 summarizes calling rate differences within and among experiments and between short and long-term experiments. Statistical values can be found in Table S1.

\section{Call structure}

A comparison of pre-trials versus trials resulted in the following. In the presence of real sound sources, playbacks of outboard engine noise, and oil-drilling sounds, significant changes in calls occurred in received levels, number of frequency-modulated calls, and the number of pulses per call. These resultant values were significantly higher during trial periods when compared to pre-trial periods. Repetition rates also increased as a result of the increasing number of pulses produced per call given that no change occurred in call duration. During the projection of killer whale sounds, all calling ceased. For Expt E (i.e. equipment on but no sounds produced) significant differences in call structure were not found, suggesting that the acoustic equipment had no effect on the calling behavior of gray whales.

When comparing the structural changes among the 5 different sound sources, received levels were shown to be the highest in the presence of outboard engine noise, followed by real sources, and then oildrilling sounds. The percent of frequency-modulated calls, the number of pulses produced per call, and repetition rates varied among experiments but were not significantly different.

Regardless of the type of sound being encountered, similar acoustic parameters changed. When comparing short-term versus long-term experiments for both real sources and outboard engine noise, no differences could be found. Resultant values are summarized in Table 2 with statistical results provided in Table S5. 


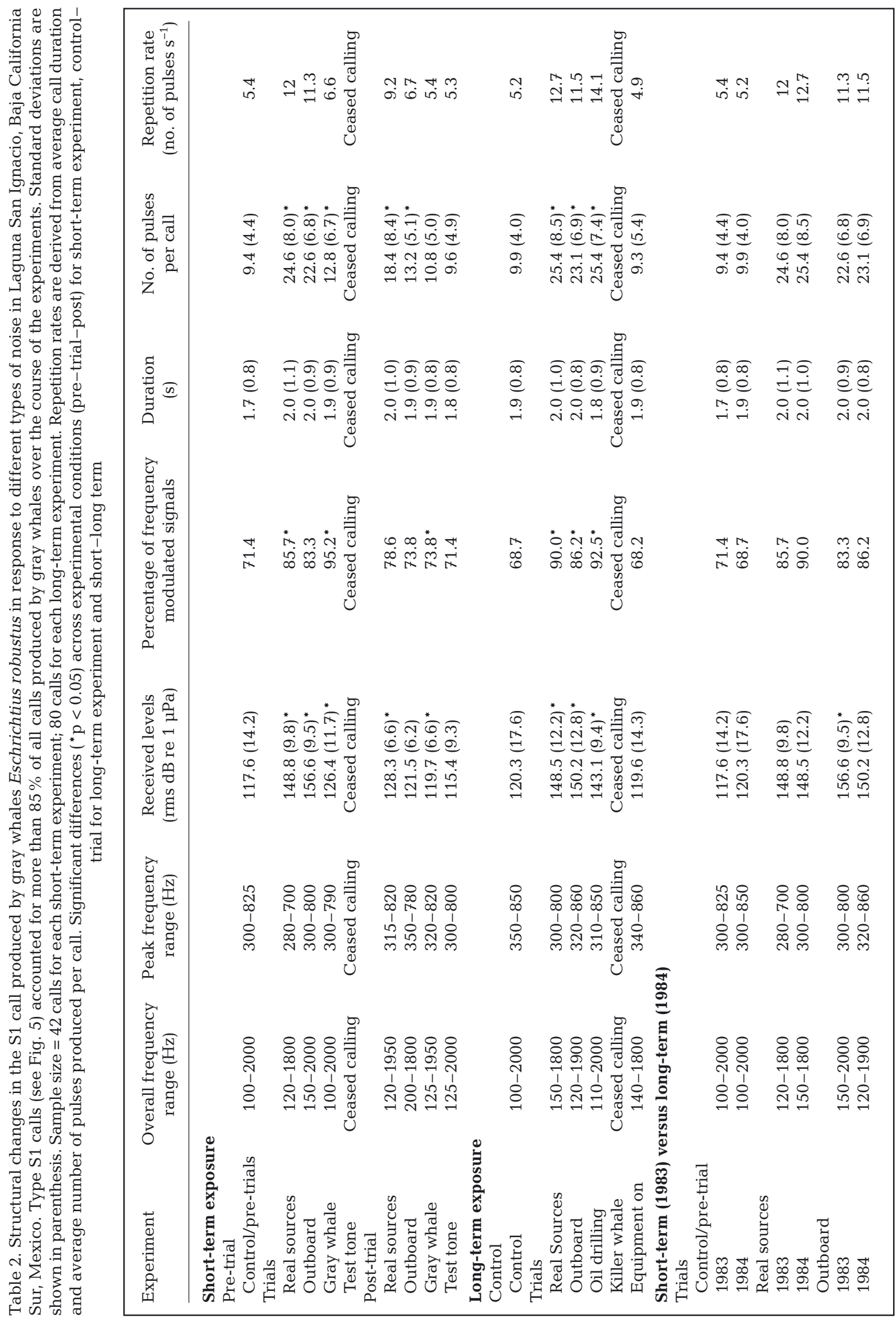


Structural comparisons between short- and long-term noise exposure

Structural changes in the calls produced by gray whales were also compared between short-term and long-term experimentation. Significant differences could not be found when comparing most of the acoustic parameters. One exception did occur during the projection of outboard engine noise. Received levels were significantly higher when whales were exposed to short-term playbacks versus long-term playbacks. Overall frequency ranges and peak frequency ranges for all experimental periods were not statistically tested given that values were all within the ranges obtained during control or pre-trial periods. Table 2 summarizes call structural differences within and among experiments and between short and long-term experiments. Resultant statistical values are shown in Table S5.

\section{DISCUSSION}

Although completed 3 decades ago, this study represents the only gray whale playback experiment which examines the effect of increased biological and anthropogenic noise on the acoustic behavior of this species.

When different sources of noise were added to their habitat, gray whales were shown to significantly modify their calling behavior. Of 9 acoustic parameters inspected, 5 changed in the presence of noise. Similar acoustic parameters were found to change when comparing experimental periods. As real and simulated noise levels increased, associated increases were documented in calling rates, received levels, percentage of calls exhibiting frequency modulation, number of pulses produced per call, and average repetition rates. The increase in received levels could be due to whales calling louder or whales being closer to the hydrophone. Because we did not control for the distance of whales to the hydrophone, we assumed any change in spatial distribution during the exposure trial (over multiple days) would result in displacement away from the noise source, as documented in other studies (Bryant et al. 1984, Dahlheim 1987). Changes were not documented to occur in call type, frequency ranges, peak frequency ranges, and call duration. Comparing real to simulated sources also suggested that playback experiments are a valid way to assess noise impacts on whales. This also indicates that noise alone changes the behavior of whales, suggesting that quieting the source would help reduce the impact. Comparisons between post-trial and pre-trial/control periods indicated that calling returned to normal at different rates depending on the sound stimuli. The resultant changes made in the $\mathrm{S} 1$ call during trial periods suggest that both signal transmission and reception would be enhanced. When calls are produced more frequently (i.e. increasing calling rates, number of pulses per call, and number of pulses per second) and at a higher source level (increase in signal output), signal transmission and reception would be increased. Our results are in accordance with the Lombard effect documented in north Atlantic right whales (Parks et al. 2011), humpback whales (Dunlop et al. 2014) and beluga whales Delphinapterus leucas (Scheifele et al. 2005). These whales responded to periods of increased noise by increasing call amplitude. Increasing the percentage of frequency-modulated calls also has advantages; they carry more information and travel greater distances (Wiley \& Richards 1978).

A comparison between short and long-term noise exposure provided insights into the acoustic capabilities and strategies employed by this species. When comparing short-term to long-term responses, significant differences were found among experiments in both calling rates and call structure. The types of acoustic parameters that changed between these trial periods were similar; however, significant differences occurred in the amount of change. Shortterm experiments represented a temporary and rapid onset of noise which may have resulted in a startled response by whales, which could cause an individual to elicit a more rapid change in calling behavior. Conversely, long-term playback periods represented a more gradual onset of noise. As whales move toward a noise source levels would increase with a corresponding decrease as they moved past the noise source. The collective results imply that gray whales vary their call behavior based upon the type of noise encountered, its duration, and presentation.

Novel stimuli resulted in a radical departure in the acoustic behavior of the gray whale. In the presence of oil-drilling sounds, calling rates were significantly reduced. During the projection of test tones and killer whale sounds, all calling ceased. One would predict that a significant reduction in calling or a complete cessation of calling would be detrimental for an acoustically dependent animal. However, in some situations signal reduction may be beneficial. The benefits of the prey (i.e. gray whales) remaining silent in the presence of a predator (i.e. killer whales) are 
obvious. If gray whales remain undetected by their predators, then certainly this acoustic strategy provides a selective advantage to this species. This silent behavior by gray whales while being pursued by killer whales in the Bering Sea has also been reported by Ljungblad \& Moore (1983). There is also evidence of a decrease or even a ceasing of calls in the acoustic activity of odontocetes in the presence of natural predators. This acoustic response has also been observed in both captive and free-ranging beluga whales (Morgan 1979, Lésage et al. 1999, Karlsen et al. 2002, Van Parijs et al. 2003, Castellote \& Fossa 2006) and free-ranging narwhals Monodon monoceros (Finley et al. 1990) and has been associated with threat, startle, fright, alarm, or stress contexts and interpreted as a survival strategy to avoid detection by predators (Schevill 1964, Fish \& Vania 1971, Morgan 1979, Finley et al. 1990, Lésage et al. 1999). A playback study on North Atlantic right whales documented a drastic cessation in foraging behavior and interruption of the diving cycle when an alarm signal was projected, independently of the received level (Nowacek et al. 2004). The alarm, while more complex than the test tone used in the present study, was also a swept tone. The study by Nowacek et al. (2004) exposed right whales to projected ship noise without any obvious response. These results resemble the differential behavioral responses obtained here, where elicited gray whale responses were related to the degree of novelty and habituation to the noise stimuli.

It is possible that when confronted with unknown sound sources the best strategy is to remain silent. In the case of oil-drilling sounds, other factors were considered. Given the extensive geographic range of this species, gray whales have been exposed to a wide variety of industrially related sources; thus prior exposure to oil-drilling sounds was assumed. When oil-drilling sounds were encountered in their breeding lagoons, calling rates were significantly reduced. When they did call, signals were modified to ensure adequate transmission. The reduction in calling rate may represent an additional strategy in the random timing of the projected signal. Call reduction would provide certain benefits in temporary situations but if prolonged may result in deleterious impact on an acoustically dependent animal. It is possible that whales decreased their call rates due to the increased effort it takes to make the necessary changes in response to noise (e.g. an increase in call amplitude in higher noise conditions). Alternatively, whales may be calling only when there is a temporary reduction in the background noise level, in particular when noise conditions are prolonged (Lésage et al. 1999, Sun \& Narins 2005, Parks et al. 2007).

Interestingly, gray whales did not change the call frequency ranges, the range of peak frequencies or signal duration under any of the noise conditions included in this study. In contrast, other mysticete whales have shown adaptability to the frequency range of their vocalizations during elevated noise conditions (Parks et al. 2011, Castellote et al. 2012, Melcón et al. 2012). The different acoustic characteristics of gray whale calls (Dahlheim et al. 1984) compared to the more tonal signals produced by other mysticetes could impose physical limitations for frequency shifts during sound production.

Ocean sound levels will most likely continue to increase, in particular in coastal environments (Hildebrand 2009). Although gray whales were capable of acoustically responding in a variety of ways during our study, there must be some physical (either anatomical or physiological) limitation in which calls can be modified. For example, there undoubtedly must be a limit to the maximum source level that an animal can produce (Bradbury \& Vehrencamp 1998). When background noise levels exceed the gray whale acoustic behavioral plasticity documented here, the whales' communication range will be reduced. Another option to avoid noise is for animals to wait until the noise levels are lower to begin calling; however, a delay in calling could potentially compromise vital social functions. Recent results from bowhead whales exposed to grading levels of seismic survey noise are supportive of this mechanism (Blackwell et al. 2015). In addition, there must be some level of sensitivity to particular sound sources due to the hearing sensitivities or past experience of these whales to the noise source. The level of tolerance or sensitivity may significantly vary with respect to the individual, group size, age, reproductive states, behavior, and the part of the range occupied by this species.

The conclusions based upon our acoustic investigations have shown that increased levels of noise had a profound effect on the calling behavior of gray whales. The call modifications made by gray whales documented here were shown to enhance both signal transmission and reception. Whether these call modifications are sufficient to remain effective in higher noise situations remains to be tested. Whale responses were shown to vary with respect to noise based on exposure time, the way in which the signal was presented, and the type of sound stimuli present in the environment. The plasticity observed in gray whale acoustic behavior, when exposed to increased 
levels of noise, most likely enables this species to cope with the dynamic noise situations that typically characterize its coastal habitats. However, it is unknown whether or not the changes documented during this study are completely beneficial to this species. Signaling costs are higher when call structure is modified resulting in an increase in the energy needed to communicate (Bradbury \& Vehrencamp 2011). Therefore, the measured acoustic changes in gray whale signaling might compensate the masking effects of increased anthropogenic background noise (e.g. vessels, outboard engine noise) but the energy costs to the animal could be higher. Furthermore, changes in acoustic behavior may affect the information codified in their calls. Calling rate as well as call structure modifications might affect communication effectiveness, in particular changes in parameters that might be related to the motivational state of the caller (Morton 1977).

Although the function of gray whale calls is still unknown, it is presumed to be directly related to vital life processes (e.g. social, foraging, navigation). Therefore, a reduction in acoustic communication space, increased efforts to communicate, and a potential decrease in calling functionality could have negative effects for the whale's reproduction success, and ultimately its survival. This is of particular concern for a migratory coastal species like the gray whale whose preferred habitat is chronically exposed to disturbances in both its winter breeding habitat (e.g. whale watching, increased maritime traffic and pleasure boats) and its summer feeding habitat (e.g. Arctic oil and gas exploration).

Exposure to several decades of long-term ocean noise documented significant changes in the calls produced by both North Atlantic right whales Eubalaena glacialis and South Atlantic right whales E. australis. A shift to higher frequencies occurred in the right whales upsweep calls in response to the decadal increase that has occurred in the overall levels of ocean background noise (Parks et al. 2007). Given that this gray whale study was conducted 3 decades ago, and ocean background noise has increased over this time period (McDonald et al. 2006), new gray whale recordings in Laguna San Ignacio would allow testing to determine if changes have occurred in this species acoustic behavior in response to increased levels of background noise.

Disclaimer. Mention of trade names is for identification purposes only and does not imply endorsement by NOAA, National Marine Fisheries Service, Alaska Fisheries Science Center.
Acknowledgements. We are most indebted to the Mexican government (Departmento de Pesca) that gave us permission to conduct this study. Our gratitude is also extended to several agencies and universities who assisted at various stages of this research. We thank the Naval Acoustic Range (Bremerton, WA), Hubbs/Sea World Research Institute (San Diego, CA), American Cetacean Society (San Pedro California Chapter), Applied Physics Laboratory (Seattle, WA), National Marine Fisheries Service, National Marine Mammal Laboratory (Seattle), the University of British Columbia (Vancouver) and the University of Washington (Seattle). A special thank you is extended to the tour vessels operating out of San Diego that provided unending support by resupplying us with food, water, and fresh-water showers: $M / V$ 'Pacific Queen', M/V 'Royal Polaris', and M/V 'Searcher'. A special thanks to Janice Waite and Sonja Kromann for their assistance at various stages of this manuscript. Phillip Clapham, Kate Stafford, and Catherine Berchock provided valuable reviews. Our deepest appreciation and sincerest thanks are extended to the 5 people who supported us throughout this multi-year research project in countless ways: Howard Braham, H. Dean Fisher, Steve Swartz, Mary Lou Jones, and Bob Dahlheim.

\section{LITERATURE CITED}

Barber JR, Crooks KR, Fristrup KM (2010) The costs of chronic noise exposure for terrestrial organisms. Trends Ecol Evol 25:180-189

Blackwell SB, Nations CS, McDonald TL, Thode AM and others (2015) Effects of airgun sounds on bowhead whale calling rates: evidence for two behavioral thresholds. PLOS ONE 10:e0125720

Bradbury JW, Vehrencamp SL (1998) Principles of animal communication. Sinauer Associates, Sunderland, MA

Bradbury JW, Vehrencamp SL (2011) Principles of animal communication, 2nd edn. Sinauer Associates, Sunderland, MA

> Brumm H, Slabbekoorn H (2005) Acoustic communication in noise. Adv Stud Behav 35:151-209

Bryant PJ, Lafferty CM, Lafferty SK (1984) Reoccupation of Laguna Guerrero Negro, Baja California, Mexico, by gray whales. In: Jones ML, Swartz SL, Leatherwood S (eds) The gray whale Eschrichtius robustus. Academic Press, New York, NY, p 375-387

Castellote M, Fossa F (2006) Measuring acoustic activity as a method to evaluate welfare in captive beluga whales (Delphinapterus leucas). Aquat Mamm 32:325-333

> Castellote M, Clark CW, Lammers MO (2012) Acoustic and behavioural changes by fin whales (Balaenoptera physalus) in response to shipping and airgun noise. Biol Conserv 147:115-122

Clark CW, Ellison WT, Southall BL, Hatch L, Van Parijs SM, Frankel A, Ponirakis D (2009) Acoustic masking in marine ecosystems: intuitions, analysis, and implication. Mar Ecol Prog Ser 395:201-222

Creel S, Fox JE, Hardy A, Sands J, Garrott R, Peterson R (2002) Snowmobile activity and glucocorticoid stress responses in wild wolves and elk. Conserv Biol 16: 809-814

Dahlheim ME (1987) Bio-acoustics of the gray whale (Eschrichtius robustus). PhD thesis, University of British Columbia, Vancouver

Dahlheim ME, Fisher HD, Schempp J (1984) Sound produc- 
tion by the gray whale and ambient noise levels in Laguna San Ignacio, Baja California Sur, Mexico. In: Jones MJ, Swartz SL, Leatherwood S (eds) The gray whale, Eschrichtius robustus. Academic Press, New York, NY, p 511-541

Di Iorio L, Clark CW (2010) Exposure to seismic survey alters blue whale acoustic communication. Biol Lett 6: 51-54

Dunlop RA, Cato DH, Noad MJ (2014) Evidence of a Lombard response in migrating humpback whales (Megaptera novaeangliae). J Acoust Soc Am 136:430-437

Finley KJ, Miller GW, Davis RA, Greene CR (1990) Reactions of belugas, (Delphinapterus leucas), and narwhals, (Monodon monoceros), to ice-breaking ships in the Canadian High Arctic. Can Bull Fish Aquat Sci 224: 97-117

Fish JF, Vania JS (1971) Killer whale, Orcinus orca, sounds repel white whales, Delphinapterus leucas. Fish Bull 69: 531-535

Hildebrand A (2009) Anthropogenic and natural sources of ambient noise in the ocean. Mar Ecol Prog Ser 395:5-20

> Jefferson TA, Stacey PJ, Baird RW (1991) A review of killer whale interactions with other marine mammals: predation to co-existence. Mammal Rev 21:151-180

Jones ML, Swartz SL (1984) Demography and phenology of gray whales and evaluation of whale-watching activities in Laguna San Ignacio, Baja California Sur, Mexico. In: Jones ML, Swartz SL, Leatherwood S (eds) The gray whale Eschrichtius robustus. Academic Press, New York, NY, p 309-374

Karlsen JD, Bisther A, Lyderse C, Haug T, Kovacs KM (2002) Summer vocalizations of adult male white whales (Delphinapterus leucas) in Svalbard, Norway. Polar Biol 25: 808-817

Kight CR, Swaddle JP (2011) How and why environmental noise impacts animals: an integrative, mechanistic review. Ecol Lett 14:1052-1061

Lésage V, Barrette C, Kingsley MCS, Sjare B (1999) The effect of vessel noise on the vocal behavior of belugas in the St. Lawrence River Estuary, Canada. Mar Mamm Sci 15:65-84

Ljungblad DK, Moore SE (1983) Killer whales (Orcinus orca) chasing gray whales (Eschrichtius robustus) in the Northern Bering Sea. Arctic 36:361-364

Lombard E (1911) Le signe de l'élévation de la voix. Ann Mal Oreil Larynx 37:101-199

Malme CI, Miles PR, Miller GW, Richardson WJ, Roseneau DG, Thompson DH, Greene CR Jr (1989) Analysis and ranking of the acoustic disturbance potential of petroleum industry activities and other sources of noise in the environment of marine mammals in Alaska. Report produced for US Minerals Management. BBN Systems and Technological Corporation, Cambridge, MA

McDonald MA, Hildebrand JA, Wiggins SM (2006) Increase in deep ocean ambient noise in the Northeast Pacific west of San Nicolas Island, California. J Acoust Soc Am 120:711-718

McDonald M, Hildebrand J, Mesnick S (2009) Worldwide decline in tonal frequencies of blue whale songs. Endang Species Res 9:13-21

Melcón ML, Cummins AJ, Kerosky SM, Roche LK, Wiggins SM, Hildebrand JA (2012) Blue whales respond to anthropogenic noise. PLOS ONE 7:e32681

Moore SE, Clark JT (2002) Potential impact of offshore human activities on gray whales (Eschrichtius robustus).
J Cetacean Res Manag 4:19-25

Moore SE, Ljungblad DK (1984) Gray whales in the Beaufort, Chukchi, and Bering Seas: distribution and sound production. In: Jones ML, Swartz SL, Leatherwood S (eds) The gray whale, Eschrichtius robustus. Academic Press, New York, NY, p 543-559

Morgan DW (1979) The vocal and behavioural reactions of the beluga, Delphinapterus leucas, to playback of its sounds. In: Winn HE, Olla BL (eds) Behaviour of marine animals: current perspectives in research, Vol 3: Cetaceans. Plenum Press, New York, NY, p 311-343

Morton ES (1977) On the occurrence and significance of motivation-structural rules in some bird and mammal sounds. Am Nat 111:855-869

> Nowacek DP, Johnson MP, Tyak PL (2004) North Atlantic right whales Eubalaena glacialis ignore ships but respond to alerting stimuli. Proc R Soc B 271:227-231

> Nowacek DP, Thorne LH, Johnston DW, Tyack PL (2007) Responses of cetaceans to anthropogenic noise. Mammal Rev 37:81-115

NRC (National Research Council) (2003) Ocean noise and marine mammals. National Academy Press, Washington, $\mathrm{DC}$

NRC (National Research Council) (2005) Marine mammal populations and ocean noise: determining when noise cases biologically significant effects. National Academies Press, Washington, DC

> Parks SE, Clark CW, Tyack PL (2007) Short- and long-term changes in right whale calling behavior: the potential effects of noise on acoustic communication. J Acoust Soc Am 122:3725-3731

Parks SE, Johnson M, Nowacek D, Tyack PL (2011) Individual right whales call louder in increased environmental noise. Biol Lett 7:33-35

Parris KM, Schneider A (2008) Impacts of traffic noise and traffic volume on birds of roadside habitats. Ecol Soc 14: 29

Popper AN, Hastings MC (2009) The effects of human-generated sound on fish. Integr Zool 4:43-52

Rabin LA, McCowan B, Hooper SL, Owings DH (2003) Anthropogenic noise and its effect on animal communication: an interface between comparative psychology and conservation biology. Int J Comp Psychol 16:172-192

Richardson WJ, Greene CR, Malme CI, Thomson DH (1995) Marine mammals and noise. Academic Press, San Diego, CA

Rolland RM, Parks SE, Hunt KE, Castellote M and others (2012) Evidence that ship noise increases stress in right whales. Proc R Soc B 279:2363-2368

Scheifele PM, Andrew S, Cooper RA, Darre M, Musiek FM, Max L (2005) Indication of a Lombard vocal response in the St. Lawrence River beluga. J Acoust Soc Am 117: 1486-1492

Schevill WE (1964) Underwater sounds of cetaceans. In: Tavolga WN (ed) Marine bio-acoustics. Pergamon Press, London, p 307-316

Seip DR, Johnson CJ, Watts GS (2007) Displacement of mountain caribou from winter habitat by snowmobiles. J Wildl Manag 71:1539-1544

> Shannon G, McKenna MF, Angeloni LM, Crooks KR and others (2016) A synthesis of two decades of research documenting the effects of noise on wildlife. Biol Rev Camb Philos Soc 91:982-1005

Slabbekoorn H (2013) Songs of the city: noise-dependent spectral plasticity in the acoustic phenotype of urban 
birds. Anim Behav 85:1089-1099

Sokal RF, Rohlf FJ (1969) Biometry: the principles and practice of statistics in biological research. W. H. Freeman, San Francisco, CA

Southall BL, Bowles AE, Ellison WT, Finneran JJ and others (2007) Marine mammal noise exposure criteria: initial scientific recommendations. Aquat Mamm 33: 411-521

Sun JWC, Narins PM (2005) Anthropogenic sounds differentially affect amphibian call rate. Biol Conserv 121: 419-427

Tennessen JB, Parks SE, Langkilde T (2014) Traffic noise

Editorial responsibility: Wendy Piniak (Guest Editor),

Gettysburg, Pennsylvania, USA causes physiological stress and impairs breeding migration behaviour in frogs. Conserv Physiol 2:cou032

Van Parijs SM, Lydersen C, Kovacs KM (2003) Sounds produced by individual white whales, Delphinapterus leucas, from Svalbard during capture (L). J Acoust Soc Am 113:57-60

Wiley RH, Richards DG (1978) Physical constraints on acoustic communication in the atmosphere: implications for the evolution of animal vocalizations. Behav Ecol Sociobiol 3:69-94

Zar JH (1974) Biostatistical analysis. Prentice-Hall, Englewood Cliffs, NJ

Submitted: November 16, 2015; Accepted: August 9, 2016

Proofs received from author(s): October 21, 2016 